\title{
Probe into Standardization Development Strategy of Underdeveloped Regions in China
}

\author{
Linfeng Wu \\ China National Institute of Standardization, Beijing, 100191, China
}

\begin{abstract}
The contradiction between people's growing demand for a better life and the inadequate, imbalance development of China has become the principal contradiction in our society, from the perspective of standardization, the paper discusses the development strategy planning and design in less developed areas in our country, analyzed the existing problems, and gives the opinion suggestion, to promote China's rapid economic and social development in less developed areas, promote the coordinated development of economy and society of our country has a certain reference significance.
\end{abstract}

Keywords: imbalance; standardization; underdeveloped; planning.

\section{我国欠发达地区标准化发展战略探究}

\author{
吴林峰 \\ 中国标准化研究院, 北京, 100191, 中国
}

摘 要: 人民日益增长的美好生活需要和不平衡不充分的发展之间的矛盾已经成为当前我国社 会的主要矛盾。本文从标准化的角度探讨了我国欠发达地区的发展战略规划设计, 初步分析 了其存在的一些问题, 给出了意见建议, 对推动我国欠发达地区经济社会快速发展、推进我 国经济社会协调发展有一定参考意义。

关键词: 不平衡; 标准化; 欠发达; 规划

\section{1. 引言}

党的十九大报告指出，中国特色社会主义进入新时代，我国社会主要矛盾已经转化为人民日 益增长的美好生活需要和不平衡不充分的发展之间的矛盾。区域发展不平衡问题已经成为制 约我国经济社会持续健康发展的一个瓶颈。“全面建成小康社会”的要求的不仅仅是“小康”, 而 且是要“全面”。习近平总书记指出要坚定实施乡村振兴战略、区域协调发展战略, 突出抓重点、 补短板、强弱项, 特别是要坚决打好防范化解重大风险、精准脱贫、污染防治的攻坚战, 使 全面建成小康社会得到人民认可、经得起历史检验。发展不平衡不仅仅是我国面临的问题, 也是世界很多国家可能都会遇到并且需要共同面对的问题, 这一趋势在很多国家还在加剧。 如何推进区域协调发展，有效推进我国欠发达地区快速发展是一个值得探讨的问题。

\section{2. 我国欠发达地区的界定}

所谓欠发达地区, 是指那些有一定经济实力和发展潜力但与发达地区相比还有一定差距, 生 产力发展不平衡，科技水平还不发达的区域。[1]发达地区不同学者、文件有不完全相同的 定义和界定, 欠发达地区所包含的地区也是一个不断动态调整和变化的, 然而, 在一定时期 内会处于动态稳定的状态, 包含的省市可能也是固定的。我国学者对“欠发达地区”的内涵与定 义方法进行了长期研究, 并对我国“欠发达地区”的范围进行了界定。

我国对欠发达地区界定主要有三种划分法。[2]一是地域划分法。在“七五”计划中将我国粗略 的分为东部发达地区和中西部欠发达地区，对欠发达地区进行过界定。欠发达地区经济发展 研究中心[3]于 2009 年在中国经济出版社出版的《欠发达地区经济发展研究 (一)》中, 对欠 
发达地区进行了界定, 把包含四川、青海在内的 20 多个省(区、市)划归到了欠发达地区。二 是单一经济划分法。胡鞍钢 [4] 以省为单元将人均 GDP 低于全国平均水平的地区划为欠发达地 区，包括贵、皖等 9 个省区为欠发达地区。杨晓光等[5]以县为单元, 将人均 GDP 低于全国平 均水平 60\%的县 (县级市) 列为欠发达地区。对于革命老区、边境地区、少数民族地区、库区 和自然条件恶劣的地区适当放宽标准，最终划入欠发达地区的县（市）共有 808 个。三是综 合划分法。杨伟民[6]借用人类发展指数的方法, 用人均收入等 10 个指标合成发展程度指数, 在省级单元将陕西、四川等 10 个省区划为欠发达的地区。王雷等[7]用 21 个指标对我国各省 发达程度进行聚类, 并通过连续三年的数据分析, 来划分我国发达地区、欠发达地区和落后 地区。林勇[8]从分析欠发达地区内涵和社会发展水平衡量方式入手, 运用 IDI 指标体系, 实 例测算并给出了欠发达省份范围。另外, 张鹏飞[9]构建了欠发达地区的四层指标体系, 并通 过指标体系的综合评价，界定了我国欠发达地区。总体汇总对比情况如表 1 。

\section{表1 欠发达地区界定}

\begin{tabular}{|c|c|c|c|}
\hline 划分主体 & 划分单元 & 划分方法 & 欠发达地区 \\
\hline 国家（“七五” 时期） & 省区市 & 地域划分法 & $\begin{array}{c}\text { 山西、内蒙古、吉林、黑龙江、安徽、江西、河南、湖北、湖南、广西、四川、 } \\
\text { 贵州、云南、西藏、陕西、甘肃、青海、宁夏和新疆 }\end{array}$ \\
\hline 胡鞍钢 (1994) & 省区市 & $\begin{array}{l}\text { 单一经济划分法 (人均 } \\
\text { GDP) }\end{array}$ & $\begin{array}{c}\text { 贵州、安徽、广西、甘肃、河南、云南、四川、江西、湖南、陕西、西藏、宁 } \\
\text { 夏、内蒙、山西、河北、湖北、青海、海南和吉林 }\end{array}$ \\
\hline 杨伟民（1997） & 省区市 & $\begin{array}{c}\text { 综合划分法 (发展程度指 } \\
\text { 数) }\end{array}$ & 四川、陕西、广西、宁夏、新疆、青海、甘肃、云南、贵州和西藏 \\
\hline 王雷 (2006) & 省区市 & 综合划分法 & $\begin{array}{c}\text { 欠发达地区包括：河北、山西、辽宁、吉林、黑龙江、安徽、江西、河南、湖 } \\
\text { 北、湖南、广西、海南、重庆、四川; 落后地区包括：内蒙古、贵州、云南、陕 } \\
\text { 西、甘肃、青海、宁夏、新疆、西藏 }\end{array}$ \\
\hline 林勇 (2007) & 省区市 & $\begin{array}{c}\text { 综合划分法 (IDI 指标体 } \\
\text { 系) }\end{array}$ & $\begin{array}{c}\text { 陕西、重庆、宁夏、青海、河南、湖南、江西、四川、安徽、西藏、甘肃、广 } \\
\text { 西、海南、云南和贵州 }\end{array}$ \\
\hline $\begin{array}{l}\text { 贵州省高等学校人文社科基地， } \\
\text { 贵州省财经学院欠发达地区经济 } \\
\text { 发中心 (2009) }\end{array}$ & 省区市 & 地域划分法 & $\begin{array}{c}\text { 河南，河北省，湖北鄂西，欠发达地区包括燕山坝上地区、黑龙港地区、太行山 } \\
\text { 地区、沿海盐碱地区西部十二省区重庆，四川，贵州，云南，西藏，陕西，甘 } \\
\text { 肃，青海，宁夏，新疆，内蒙古，广西。 }\end{array}$ \\
\hline 谷树忠、张新华等 (2011) & 地市州盟 & 综合划分法 & 137 个欠发达地区 \\
\hline 张鹏飞 (2016) & 省区市 & 综合划分法 & $\begin{array}{c}\text { 江西、四川、湖南、黑龙江、海南、广西、宁夏、新疆、云南、青海、西藏、甘 } \\
\text { 肃以及贵州 }\end{array}$ \\
\hline 肖萍 (2016) & 省区市 & 地域划分法 & $\begin{array}{c}\text { 河南省、河北省欠发达地区 (包括燕山坝上地区、黑龙港地区、太行山地区、沿海 } \\
\text { 盐碱地区)、吉林省延边州以及西部 } 12 \text { 省、自治区包括重庆、四川、贵州、云 } \\
\text { 南、西藏、陕西、甘肃、青海、宁夏、新疆、内蒙古、广西 }\end{array}$ \\
\hline
\end{tabular}

通过对表 1 中前期国内专家、学者对我国欠发达地区范围界定的梳理不难发现，四川、贵州、 云南、广西、宁夏、青海、甘肃等地多年来一直都是公认的我国欠发达地区。

\section{3. 标准化战略与区域协调发展}

区域发展不平衡的原因, 既包括自然、历史、教育等, 也与世界经济整体态势影响以及地方 战略政策息息相关。其中, 固有的自然环境很难改变、历史情况也已经形成。政府是影响中 国不同地区人均 GDP 差距的一个重要角色。不同地区战略政策的差异, 会影响地区经济的发 
展。不仅如此, 中国政府的 GDP 政绩考评体系[10]和政府调控[11]也会导致不同地区政府投资 的激烈竞争而引发“诸侯经济”的产生, 一定程度上导致国内的市场分割, 从而造成不同地区人 均 GDP 的差异。因此, 区域协调发展能否早日实现与地方政府战略政策是否切实有效关系密 切, 欠发达地区政府的战略规划的优化设计和布局是促进其快速发展、缩小与发达地区差距 至关重要的因素。

标准是经济社会活动的技术依据，是推进区域协调发展的重要制度工具，是国家基础性制度 建设的重要内容, 也是促进国家治理体系和治理能力现代化的有效手段。标准在经济、社会 发展中具有基础性、支撑性和引领性的作用。因此在着力解决区域经济发展不平衡、不充分 的问题时要充分利用标准这一工具, 重视标准化在建立更加有效的区域协调发展机制以及提 升政府治理能力、治理水平方面的作用。全国很多欠发达地区也都已经认识到标准化的重要 作用，结合当地实际，纷纷制定了相关的标准化发展战略、规划等。

\section{4. 我国欠发达地区的标准化规划}

2. 1. 标准化规划梳理

截至 2017 年年底, 在四川、贵州、云南、广西、宁夏、青海、甘肃七个欠发达地区的省、自 治区中, 均已经发布过如标准化相关的发展规划、纲要、意见、通知等战略性文件，表 2 梳 理了相关文件、规划的名称及发布日期等信息。

表2 欠发达地区标准化相关规划表

\begin{tabular}{|c|c|c|c|}
\hline 序号 & 地区 & 标准化与质量提升相关规划 & 日期或文号 \\
\hline \multirow{3}{*}{1.} & \multirow{3}{*}{ 四川 } & 四川省旅游标准化发展规划(2011 - 2015) & 2010.11 .09 \\
\hline & & 四川省标准化体系建设发展规划（2016） & 2016.12.18 \\
\hline & & 四川省开展基层政务公开标准化规范化试点工作实施方案 & 2017.09 .06 \\
\hline \multirow{3}{*}{2.} & \multirow{3}{*}{ 贵州 } & 贵州《省人民政府关于加强标准化工作的若干意见》 & 2010.05 .04 \\
\hline & & 贵州省标准化体系建设发展规划(2016-2020年) & 2016.12.26 \\
\hline & & 贵州省开展基层政务公开标准化规范化试点实施方案 & 2017.08 .24 \\
\hline \multirow{3}{*}{3.} & \multirow{3}{*}{ 云南 } & 云南省人民政府关于实施标准化发展战略的意见 & 云政发 (2009) 143号 \\
\hline & & 云南省人民政府办公厅关于加快推进标准化体系建设的实施意见 & 云政办发〔2016〕149号 \\
\hline & & 云南省开展基层政务公开标准化规范化试点工作方案 & 2017. 08.25 \\
\hline 4. & 广西 & 广西壮族自治区人民政府关于实施技术标准发展战略的意见 & 桂政发〔2008〕55号 \\
\hline 5. & 宁夏 & 宁夏回族自治区标准化体系建设发展规划（2016-2020） & 2017.02.24 \\
\hline 6. & 青海 & 青海省人民政府办公厅转发省质量技术监督局关于实施标准化战略意见的通知 & 青政办〔2007〕95号 \\
\hline 7. & 甘肃 & 甘肃省标准化发展战略纲要 (2014) & 2014.11.15 \\
\hline
\end{tabular}

\section{2. 规划内容简析}

通过对这些文件内容的初步分析发现, 我国欠发达地区标准化战略规划设计多以战略纲要, 省市政府加强相关工作意见、通知、发展规划, 实施方案等形式出现, 对各地标准化工作的 总体要求、发展目标、主要任务、重点工作、配套措施等内容进行了规划设计。这些规划相 关的文件主要以“政府推动、市场导向、企业主体、社会参与”作为工作的导向, 结合各省市产 
业特色和发展重点, 在标准化方面, 提出了健全标准体系、强化标准实施应用、加强标准监 督管理、营造社会共治氛围、加强国际标准化工作、夯实标准化工作基础等工作，各地区根 据各地特点，一般都是从农业农村、工业、服务业、社会管理及公共服务、生态文明建设等 层面制定相应措施，保证标准化规划的实施。

虽然欠发达地区标准化战略规划设计与发达地区相比还存在一些差距, 但是标准化战略规划 的发布和实施, 为引领和推动欠发达地区产业结构的调整优化升级、促进地区经济发展方式 的转变、提升区域竞争力, 提升社会管理和公共服务水平等方面发挥了一定作用。然而，多 年来发展虽然取得了一定成效, 但是没能从根本上改变欠发达的局面, 规划设计方面还有进 一步加强和完善的空间。

2.3. 规划存在的差距

从总体上来看, 欠发达地区在标准化规划与发达地区标准化规划相比, 还存在以下差距 : 一 是欠发达地区标准化发展规划更多倾向于标准体系的完善、标准化工作的加强, 存在科技创 新能力不足、产业竞争力不够, 国际标准化影响力欠缺等差距。二是部分欠发达地区存在简 单的转载国家标准体系规划内容的问题, 部分规划设计偏重于形式化, 实施效果欠佳, 对地 区产业情况的结合等方面还存在一定欠缺。三是在标准化促进区域发展方面, 部分地区存在 片面的追求标准数量, 与实际成效结合方面的考虑不够。四是部分标准化发展战略的规划设 计偏于陈旧，与新形势、新趋势不完全符合。

\section{5. 建议}

结合以上针对欠发达地区标准化发展规划的探索研究和分析, 针对当前欠发达地区的标准化 战略规划设计提出以下几方面建议：

1 . 深入研究和分析与本地产业特色相近发达地区标准化发展规划设计, 紧跟国际、国家标准 化发展总体规划设计, 定期组织调研和学习研究, 总结相关成熟经验, 进行适用性分析和探 索。

2. 善于抓住国家针对欠发达地区倾斜政策及其他历史机遇, 充分发挥地方特色和优势, 加强 标准化应用领域的拓展、创新和应用研究。

3. 标准化发展战略的规划设计不是一劳永逸的, 还需要结合发展现状以及国家宏观政策进行 相应调整和不断完善。

\section{Acknowledgements}

The study in this article is funded by special standardization system construction in key areas research of national standardization strategic positioning, target and key tasks(572017B-572017), chairman of ISO support system policy research(572015B-4101), standardized development report(572016B-4628) and industry standardization economic benefit evaluation, part 1: principle(572018B-0046).

\section{References}

[1]. XIAO Ping. On Expression and Implementation of the Less Developed Regions' Interests in Local Legislation, Legal Forum, 2016(01):15-22

[2]. GU Shu-zhong etc.Features and Functional Orientation of Underdeveloped Resource-rich Regions, 2011(33):10-17

[3]. Provincial Social Science and Social Science Base of Higher Education Institutions, and Economic Development Research Center of Underdeveloped Regions of Guizhou University of 
Finance and Economics.Research of Economic Development in Less Developed Regions(1)[M]. Beijing:China Economic Press,2009:12

[4]. HU An-Gang.Research for Development in Underdeveloped Areas, Reform, 1994(3):8

[5]. YANG Xiao-Guang WANG Chuan-Sheng SHENG Ke-Rong. Research on Models and Types of Less-developed Region Based on Natural and Human Factors, Journal of the Graduate School of the Chinese Academy of Sciences, 2006(01):97-104

[6]. YANG Wei-Min. Analysis of the Definition and Characteristics of China's Undeveloped Areas, Economic reform and development, 1997,4:52-56

[7]. Wang Lei etc.Further division of the degree of regional development in China[J].Statistics \& Decision,2006(2):51-53

[8]. LIN Yong etc. Applied Analysis on Criterion and Index System of Underdeveloped Region[J], Journal of Chongqing University(Natural Science Edition), 2007(30):119-124

[9]. Zhang Peng-Fei etc.Cognitive reconstruction in underdeveloped areas: an analytical framework[J],Modern Economic Information, 2016(07):466-469

[10]. DU Ya-Jun etc,Management World, 2012(11):170-171

[11]. Li Jing etc.Study on the Spatial correlation and explanation of regional economic growth in China -- Based on analytic network process [J].Economic Research .2014(11):6-18 